\title{
PERSPECTIVAS DE GÉNERO: UNA PRIORIDAD TRANSVERSAL DEL G20 2018.
}

\author{
GENDER PERSPECTIVES: A TRANSVERSAL PRIORITY OF THE G20 2018.
}

\section{Eduardo Cuestas}

El enfoque transversal ha asegurado que las perspectivas de género se hayan tenido en cuenta en todas las líneas de trabajo propuestas, lo que ha llevado a un progreso concreto hacia el logro de una perspectiva de desarrollo más justa.

Con una visión centrada en las personas, la presidencia argentina del G20 ha empleado una estrategia de integración de género en su agenda este año. Como se indica en la visión de la presidencia argentina, el objetivo es impulsar el empoderamiento de las mujeres, la eliminación de las disparidades de género en el empleo, la ciencia, la tecnología y la educación, junto a la protección contra todas las formas de violencia de género.

Durante el transcurso de la reunión, los participantes acordaron un menú integral de políticas públicas para abordar el futuro del trabajo que exige "considerar políticas para apoyar una mayor participación de las mujeres en la educación, investigación, innovación, industrias y las empresas (STEM)"

El menú también señalaba la necesidad de equilibrar la maternidad y el trabajo: "Las políticas podrían ser consideradas para facilitar la participación de las mujeres en la fuerza laboral, al mejorar el acceso a servicios de cuidado infantil de calidad o reducir los desincentivos en algunos sistemas tributarios para que trabajen las personas de segunda edad".

La importancia de una perspectiva de género se destacó en el comunicado emitido en la Tercera Reunión de Ministros de Finanzas y Gobernadores del Banco Central, que reunió a más de 50 líderes económicos mundiales en Buenos Aires en julio de este año.

Un mes antes de esta reunión, el comunicado de la Reunión Ministerial de Transiciones de Energía en Bariloche reafirmó el compromiso de los países del G20 para promover el "acceso universal a la energía, con especial énfasis en la necesidad de erradicar la pobreza energética y garantizar la igualdad de género en toda la cadena de valor".

A fines de julio, la declaración preparada por los ministros de agricultura del G20 en Buenos Aires puso énfasis en las oportunidades e impactos potenciales que tienen las TIC, particularmente en las mujeres.

Según estimaciones de la Organización para la Cooperación y el Desarrollo Económicos (OCDE), aproximadamente 250 millones de mujeres menos que hombres están en estas lineas de estudio y trabajo. Además, las mujeres representan solo el $20 \%$ de los estudiantes graduados en carreras de TIC.

El género también jugó un papel central en las discusiones celebradas durante la Reunión Ministerial de Economía Digital en Salta en agosto. La declaración de la reunión incluyó un apéndice con iniciativas destinadas a cerrar la brecha digital entre hombres y mujeres. Altos funcionarios identificaron los principales obstáculos para la participación femenina en la digitalización. Estos incluyen acceso, falta de educación, habilidades y conocimientos tecnológicos, y prejuicios de género y normas socioculturales inherentes.

En este sentido, en una declaración conjunta preparada en Mendoza en septiembre, los ministros de educación y empleo del G20 subrayaron la necesidad de incluir a las mujeres en todos los niveles de educación, especialmente en los programas para desarrollar habilidades STEM. El documento pedía "promover la distribución equitativa de las responsabilidades de cuidado, mejorar la conciliación de la vida laboral y familiar, y aumentar la prestación de servicios de cuidado infantil, a fin de facilitar la continuación de los estudios y el desarrollo profesional".

La declaración emitida por los ministros de educación elogió el hecho de que "la presidencia argentina ha colocado la igualdad de género y el empoderamiento de las mujeres en el centro de su agenda sobre los compromisos anteriores del G20". Sin embargo, los participantes de la reunión reconocieron que a pesar

1 Editor Jefe.

Recibido: 2018-11-28

DOI: http://dx.doi.org/ 10.31053/1853.0605.v75.n4.22156

(cc) Br-ne

C Revista de la Facultad de Ciencias Médicas de Córdoba 
del progreso ya logrado, las desigualdades de género y Las barreras específicas a la educación para niñas y mujeres continúan persistiendo. También subrayaron que la igualdad de acceso a una educación inclusiva, equitativa y de calidad en entornos de aprendizaje seguros en todos los niveles educativos es esencial para lograr el empoderamiento de las niñas y las mujeres.

En una declaración, los ministros de empleo expresaron un mensaje similar al resaltar la importancia de la participación de las mujeres en el trabajo y al establecer una meta concreta para que los países del G20 se reunieran: reducir la brecha de género en un $25 \%$ para 2025.

En una reunión en Buenos Aires en septiembre, el Grupo de Trabajo para el Desarrollo (DWG) acordó un conjunto de propuestas para cerrar las brechas persistentes entre mujeres y hombres al garantizar una participación más equitativa en la fuerza laboral. Estas propuestas incluyen la provisión de servicios de atención infantil de calidad e inclusivos y la mejora del acceso a la atención médica de calidad para las mujeres, especialmente las embarazadas y que están amamantando.

Estas iniciativas se complementaron posteriormente con una declaración emitida por los ministros de salud del G20 en Mar del Plata en octubre. El documento también contenía una sección sobre el papel de la mujer. "Se deben tomar medidas para cerrar las brechas de salud persistentes entre mujeres y hombres", incluyendo "un mejor acceso a la atención médica de calidad así como una participación más equitativa en la fuerza laboral de la salud".

Esperamos que estas declaraciones se transformen rápidamente en hechos concretos por medio de la implementación de procesos justos e inclusivos. 